\title{
NOSSO CAOS, NOSSO COSMOS: NOTAS SOBRE A MEMÓRIA E A CULTURA LGBT BRASILEIRA
}

\section{OUR CHAOS, OUR COSMOS: NOTES ON BRAZILIAN LGBT MEMORY AND CULTURE}

\author{
Remom Matheus Bortolozzi* \\ Felipe Areda**
}

\begin{abstract}
RESUMO: A partir das reflexões e angústias que percorrem nosso esforço empreendido na constituição de um acervo voltado para preservação, salvaguarda e instigação historiográfica da arte, memória e cultura LGBT brasileiras, esse artigo buscar tecer, ao modo de notas ensaísticas, reflexões sobre o conceito de cultura LGBT e sua ligação com o projeto político de criação de uma memória comunitária. Para esse escopo, retomaremos um arcabouço conceitual produzido por pensadoras LGBT que podem contribuir com a formação de um vocabulário de reflexão de nossa comunidade - tais como os conceitos de eu plural de Leila Miccolis, de cosmos e ethernidade de Zé Celso, de luto em Anderson Herzer, além de pensadoras estrangeiras como Susan Sontag, com a noção de sensibilidade, e de David M. Halperin, com suas investigações sobre cultura e subcultura gay e categoria gênero.

Palavras-chave: Memória LGBT; Cultura LGBT; Decolonial.
\end{abstract}

ABSTRACT: Through the reflections and distresses that follows our engaged efforts to the constitution of a collection guided to the preservation, safeguard and historiographical instigation of brazilian LGBT art, memory and culture, this article aims to fashion, through essay notes, reflexions about the LGBT's culture concept and it's conection with the designing of a community memory as a political project. For this purpose, we'll retrieve a conceptual repertory legacy of LGBT thinkers that can aid with the formation of a reflexive vocabulary from our community - such as the concept eu plural from Leila Miccolis, cosmos e ethernidade from Zé Celso, luto from Anderson Herzer, besides foreigner LGBT thinkers as Susan Sontag, with her notion of sensibility, and David M. Halperin, with his gay culture and subculture investigations and his genre concept works. KEY-WoRDs: LGBT Memory; LGBT Culture; Decolonial.

\footnotetext{
"Doutorando em Medicina Preventiva (USP), Mestre em Educação (UNB), Especialista em Gênero e Sexualidade (UERJ) e graduado em Psicologia (UFPR). Email: remombortolozzi@gmail.com

"Mestrando em Literatura (UFSC), Bacharel em Antropologia (UNB) e Licenciado em Ciências Sociais (UnB). Email: felipeareda@gmail.com
} 
"Segue-se uma MATÉRIA, que lida com materiais vividos como o contrário de recordações: torna-se memória, com cheiro não autobiográfico; apenas biofragâncias, ou bioflagrantes."

Herbert Daniel, Meu Corpo Daria Um Romance, 1984

\section{NosSOS TRAPOS, NOSSA HISTÓRIA}

Walter Benjamin nos ensina a compreender a história como campo de batalha. Nesse campo repleto de pessoas oprimidas, mortas e derrotadas, o que chamamos de bens culturais nada mais são do que despojos de guerra. Como afirma Benjamin: "Nunca houve um monumento da cultura que não fosse também um monumento da barbárie" (1987, p.222). Por isso, diferente do historicista que conta a história a partir de uma narrativa de progresso dos bens culturais, uma historiografia das subalternas sabe que "assim como a cultura não é isenta de barbárie, não o é, tampouco, o processo de transmissão da cultura" (1987, p.222-223), de modo que as pessoas oprimidas precisam tomar a história em suas mãos buscando não os monumentos da cultura, mas seus fragmentos, seus mortos, seus escombros. A instrução de Walter Benjamin para uma historiografia das pessoas subalternizadas era estar ciente da necessidade de "escovar a história a contrapelo”, indo em direção contrária a narrativa do progresso, dos monumentos, da transmissão da cultura - sabendo, enfim que "Nada do que um dia aconteceu pode ser considerado perdido" (1987, p.223). É preciso tomar a perdição em nossas mãos e dela fazer a tinta de escrita da nossa história.

A lição de Benjamin nos foi ensinada pelas obras de Leonilson (Fortaleza, 1957-1993). O artista plástico cearense - em meio a epidemia da aids e o pânico social que transformava nossos corpos, desejos e amores na própria doença - soube contaminar a vida com sua arte, com uma produção poética que se inscrevia a partir de fragmentos, escombros, ruinas. Bordando em pedaços de lençóis ou pintando com gotas de sangue, Leonilson alegoriza o esforço de construção de uma memória e de uma cultura LGBT brasileira como uma escrita desde a perdição. João Silvério Trevisan (2000, p.325), comentando a obra de Leonilson, sintetizou: "Nosso trapo, nossa arte."

Em 2010, iniciamos um projeto de constituição de um acervo voltado para preservação, salvaguarda e instigação historiográfica da arte, memória e cultura LGBT brasileiras. Passamos a nos dedicar a tarefa de aquisição de obras de arte, livros, periódicos, LPs e CDs produzidos por lésbicas, gueis, bissexuais, travestis e transexuais brasileiras, ou que tematizem a diversidade sexual e a pluraridade de expressões de gênero no Brasil. Com investimento unicamente particular - a partir de nossa parceria amorosa, estética, companheira e política -, contabilizamos no início de 2015 dois mil e quinhentos itens - ainda sem catalogação técnica. A construção desse acervo pessoal, ligada a uma vocação colecionista, nos permitiu começar a engendrar uma história subalterna, uma historiografia que se faz aos modos dos trapos bordados por Leonilson, inscrevendo narrativas pessoais-políticas-amorosas desde fragmentos. 
O colecionismo foi apontado por Walter Benjamin como alegoria de uma historiografia subalterna. Em seus escritos sobre a infância, Benjamin apresenta a vocação colecionadora ligada à forma com que a criança se relaciona com o mundo. A colecionadora - tal qual a criança que cria uma narrativa a partir de pedras e flores encontradas - ressignifica o mundo, descontextualizando objetos achados em apropriações que criam novas histórias. Ao colecionar - afirma Benjamin - "as crianças decretam a renovação da existência por meio de uma prática centuplicada e jamais complicada" (1995, p.229). Diante do Caos, a criança colecionadora cria Cosmos.

Cada pedra que ela encontra, cada flor colhida e cada borboleta capturada já é para ela princípio de uma coleção, e tudo que ela possui, em geral, constitui para ela uma coleção única. Nela essa paixão mostra sua verdadeira face, $o$ rigoroso olhar índio, que, nos antiquários, pesquisadores, bibliômanos, só continua ainda a arder turvado e maníaco. Mal entra na vida ela é caçador. Caça os espíritos cujo rastro fareja nas coisas; entre espíritos e coisas ela gasta anos, nos quais seu campo de visão permanece livre de seres humanos. (...) Seus sonhos de nômade são horas na floresta do sonho. De lá ela arrasta a presa para casa, para limpá-la, fixá-la, desenfeitiçá-la. Suas gavetas têm de tornar-se casa de armas e zoológico, museu criminal e cripta. "Arrumar" seria aniquilar... (BENJAMIN, 1995, p.39)

A colecionadora opõe-se ao arquivista. Jacques Derrida, discutindo o conceito de arquivo, lembrou que na palavra àrkhese designa, ao mesmo tempo, a ideia de comeşo e de comando indicando dois princípios coexistentes. Do lado da ideia de "começo", teríamos um princípio ontológico, de natureza ou histórico, o que nos faz buscar nos arquivos a ordem sequencial das coisas, onde elas começam. Simultaneamente, do lado da ideia de "comando", teríamos um princípio da lei, nomológico, que faz todo arquivo se erigir por meio de arcontes, aqueles que controlam e guardam os arquivos. Nas mãos dos arcontes estaria o que Derrida chama de "poder de consignação", o poder de controlar e reunir os signos em um sistema - haja vista que para existir um arquivo é preciso haver organização unificadora e totalizadora. $O$ arquivo reúne os bens culturais sob uma "verdade patriarquívica" (DERRIDA, 2001, p.13). Diante do arquivo, a criança sabe que as ações de unificação, identificação e classificação promovidas pelos arcontes faz todo documento cultural ser documento de barbárie - para a criança, organizar é aniquilar. O poder patriarcal do arquivo, a patriarquívica, contrasta com a potência infantil da ação de colecionar. Enquanto o arquivo, historicista e nomológico, estabelece conexões totalizadoras em sistemas fechados de leitura e interpretação, a colecionadora sabe ser sua coleção sempre fragmentar, incompleta, ávida pela descoberta de uma nova obra que renovará toda a coleção. Como afirma Sônia Kramer, o(a) colecionador(a) para Benjamin "é aquele[a] capaz de descontextualizar o objeto para que possa funcionar como texto, dispondo esse objeto e sua coleção de modo que, ao interagir com um objeto, cada qual (adulto[a], jovem ou criança) conheça a história desse objeto e atribua a ele um de seus inúmeros possíveis sentidos" (KRAMER, 1998, p.210). 
A patriarquívica faz com que arquivar não seja necessariamente preservar a memória. Derrida alerta que há um mal fundante nos arquivos que faz com que arquivar seja muitas vezes esquecer. Para despatriarcalizar os arquivos, não basta, portanto, só lutar para ter acesso ao seu conteúdo; é preciso sobretudo - segundo Derrida - garantir a democratização à participação na sua constituição e na interpretação de seus conteúdos. Esse debate derridiano nos orienta para o esforço político que as comunidades LGBT precisam empreender na constituição de uma memória coletiva a partir da construção de territórios despatriarcais de criação de história, de encontro de coleções, de produção democrática de arquivos mais infantis.

A partir das reflexões e angústias que percorrem nosso esforço empreendido nos últimos anos de constituição dessa coleção sempre em curso, aberto e fragmentar - e do sonho apaixonado de transformá-lo em um território de memória coletiva, esse artigo busca tecer, ao modo de notas ensaísticas, reflexões sobre o conceito de cultura LGBT e sua ligação com o projeto político de criação de uma memória comunitária. É parte dessa política a afirmação e a produção do nosso eu em coletividade, isso que Leila Miccolis chama de eu plural. Um dos grandes aprendizados dos primeiros anos do nosso movimento foi a radicalização da constituição da política da subjetividade na enunciação do $e u$. Isso significava tirar o eu do armário e afirmar um eu que vive, que sente, que deseja, que afeta e que faz política a partir da forma que vive, sente, deseja e afeta. O eu é anunciado como um individual coletivo, a arte de esfumaçar individual e social, aproveitando situações concretas de um jeito que as extrapole. Como explica a poeta Leila:

Falar em primeira pessoa, jogar nas reuniões a vivência particular como um dado político, quando então boiavam claramente as formas de repressão, a partir da família. Substituindo as palavras de ordem e os velhos chavões, surgia o eu, que está em todos nós, o eu plural, nosso emocional exposto não como uma sessão terapêutica (quem falou em doentes ou cura?), mas política e patética. E poética. Não se falava de repressão como uma palavra vaga que passava ao longe, mas da nossa própria, a que dormia e acordava conosco, na nossa cama. (MICCOLIS \& DANIEL, 1983, p.88)

Para o escopo de relacionar o conceito de cultura LGBT com o projeto político de criação de uma memória comunitária que não silencie as múltiplas vozes dos eu plurais, retomaremos um arcabouço conceitual produzido por pensadoras LGBT que podem contribuir com a formação de um vocabulário de reflexão de nossa comunidade - tais como os conceitos de cosmos e ethernidade de Zé Celso, de luto em Anderson Herzer, além de pensadoras estrangeiras como Susan Sontag, com a noção de sensibilidade, e de David M. Halperin, com suas investigações sobre cultura e subcultura gay e categoria gênero.

\section{NosSOS MORTOS, NOSSA PURPURINA}

Talvez o mais pungente poema de Anderson Herzer (Rolândia, 1962-1982) poeta transexual paranaense que construiu a 
maior parte de sua obra quando internado na Fundação Estadual do Bem-Estar do Menor (Febem) de São Paulo - seja "Mataram João Ninguém". Quase sem acesso a uma escolarização de qualidade e com precária formação literária, Herzer (1982) escreveu dentro de uma das principais instituições de controle e opressão da Ditadura Militar brasileira um manifesto pelo direito ao luto das vidas quaisquer, indigentes, indiferentes, esquecidas e ignoradas - as vidas que, por não serem estimadas, não são lastimadas.

Quando o próximo sangue jorrar daquele por quem ninguém irá chorar, daquele que não deixará nada para se lembrar

daquele em quem ninguém quis acreditar.

Quando seus olhos só puderem fitar o escuro

quando seu corpo já estiver inerte, frio e duro,

quando todos perceberem morto João Ninguém

e quando longe de todos ele será seu próprio alguém.

Tantas mãos, tantas linhas incertas, tantas vidas cobertas, sem ninguém pra sentir,

Tantas dores, tantas noites desertas tantas mãos entreabertas, sem ninguém pra acudir.

Qualquer dia vou despir-me da luta pisar em coisas brutas, sem me arrepender.

Tão difícil ver a vida assassinada quando estamos já tontos pra tentar sobreviver.

As perguntas sem respostas, sem nada, as vidas curtas e desamparadas o último grito que não foi ouvido calaram mais um homem iludido.

E no mundo não dão mais argumentos pra fugir aos lamentos

de quem sozinho falece.

Para esses, não há mais compreensão, não há mais permissão, para que se tropece.

Na televisão, o aguardo da cotação um instante ocupado, para dizer morto João Ninguém

mas a aflição ataca, a cotação subiu ou caiu?

e João morreu... ninguém ouviu.

Eu vou distribuir panfletos, dizendo que João morreu talvez alguém se recorde do João que falo eu. Falo daquele mendigo que somos pelo menos em matéria de amor, daquele amor que esquecemos de cultivar

o qual com tanto dinheiro, ninguém jamais coroou. (HERZER, 1982, pp. 153-154)

Herzer dizia que "um homem jamais morre, enquanto sua existência for recordada" (HERZER, 1982, p.161). Acreditando nesse dizer, citamos seu poema na íntegra, na afirmação política de dizer o nome desse João Ninguém que - depois de uma trajetória de abandono e negligência familiar, intensa violência policial, encarceramento e transfobia - se suicidou aos 20 anos. O livro A queda para o Alto contendo sua autobiografia e toda sua obra poética foi publicada em 1982 e se tornou um best-seller com várias edições e reimpressões, bem como inspirou o filme Vera, dirigido e escrito por Sérgio Toledo em 1987. Apesar disso, poucos da nova geração de LGBT brasileiros conhecem o nome e os poemas de 
Herzer. O tema da morte e do direito ao luto percorria seus poemas. Para Herzer, a função do poeta era a preservação da própria vida, de modo que perder um poeta era perder a potência de significação de toda a existência. No poema "A morte do poeta, ele escreve" "Agora que as palavras de afeto se acabaram, / agora que não há mais amor em meu coração, / agora que sinto que todos morreram, / porque quem nos falava de amor, está partindo." (HERZER, 1982, p.161) e no poema "Esquecido poeta morto afirma" "Todos vão esquecer que um dia eu existi / nem meus vastos prantos vão sobreviver, / versos com poeira de minha razão / sãs lembranças de um poeta solidão." (HERZER, 1982, p. 156)

Esse melancólico poeta solidão, contudo, fez de sua vida um desacato poético diante do poder político do esquecimento - que faz a existência e a memória ser direito somente de alguns. Em sua autobiografia conta que em certo momento, o diretor da Febem se apoderou de suas poesias dizendo que iria publicá-las. Contudo, ao ver a capa do esboço do livro, percebeu que o diretor usaria as poesias para enaltecer a instituição que ele denunciava, apresentando-as como resultado do desenvolvimento cultural que a Febem possibilitava nas adolescentes:

[...] tive uma discussão com o Sr. Humberto, porque pedi que ele devolvesse minhas poesias as quais ele havia pego, dizendo publicar um livro em meu nome. Mas quando vi o esboço da capa, o sangue fervia nas minhas veias pois ele me disse que não seria possível lançar um livro com meu nome enquanto eu permanecesse na FEBEM. Portanto, seria publicado em nome da
FEBEM com o título: "Os menores escrevem”. (HERZER, 1982, p.132)

Nessa ocasião, Anderson Herzer conseguiu denunciar o fato para a presidente do Movimento de Defesa do Menor, Lia Junqueira. Lia apresentou Herzer para Eduardo Matarazzo Suplicy, na época Deputado Estadual, que não só intercedeu para a devolução dos poemas, como também para sua libertação da Febem. Herzer depois foi apresentado à Rosie Marie Muraro, da Editora Vozes, que propôs que a seus poemas fosse integrada uma autobiografia, resultando no livro Queda Para o Alto - lançado infelizmente no ano do seu suicídio. Essa história mostra o esforço político de Herzer de inscrição da sua vida, obra e trajetória em uma memória coletiva e como essa vontade precisou romper o poder de consignação dos arcontes - no caso, apatriarquívica do Sr. Humberto que precisa apagar a autoria de Anderson Herzer para erigir um monumento cultural institucional com perverso título "Os menores escrevem".

A poética de Herzer nos lembra que nós, LGBT, habitamos um mundo que não somente quer nos matar, como também quer apagar os rastros de nossa existência. Na história de Herzer, sua transexualidade se intersecciona com outras vulnerabilidades intensificando ainda mais a violência e o risco - a situação de marginalidade motivada pelo abandono e negligência familiar, bem como seu posicionamento etário, como adolescente e, portanto, sujeito menor diante da legislação totalitária da época. Sua luta por inscrever sua produção para garantir o registro de sua existência e de outras pessoas 
subalternas nos ensina como é imprescindível a constituição de uma memória comunitária que grite os nomes de Joãos Ninguéns, que invoque seus e suas poetas e que nunca deixe a potência de significação da vida se esvair.

Na comunidade LGBT brasileira, um dos nossos primeiros aprendizados é a necessidade de, em um contexto de tantas mortes, romper a narrativa das perdas de vidas. Aprendemos a dizer: bicha não morre, vira purpurina. Purpurina, aquele pó corante metálico capaz de fazer brilhar alegria no que toca, tornou-se símbolo do enfrentamento do esquecimento e de como nossa vontade de existir rompe com a própria morte. Metáfora do contágio, espalha-se sem controle e limite e, em tudo que toca, marca fazendo também purpurinar. A radicalidade desse ensinamento foi tomada por Zé Celso ao narrar a morte de seu irmão no poema "A ethernidade de Luís", fazendo de sua escrita a afirmação berrante que Luís Antônio Martinez Correa (Araraquara, 1950-1987) não morreu.

Em 1987, no dia 23 de dezembro às 14 horas e trinta minutos, Luís foi assassinato com mais de cem facadas. Nesse ano, outras bichas viraram também purpurina. Os artistas plásticos Darcy Penteado e Jorge Guinle Filho morreram em decorrência do vírus da aids e o dançarino Carlinhos Machado, a Lotinha dos DziCroquettes, foi também assassinado. Em seu poema, Zé insiste que Luís não morreu, haja vista que facadas não matam o que não pode morrer: "Matar o que não Morre Dentro ou fora dos Corpos Assassinos Com Milênios de Facadas no Assassinado" (CORRÊA, 2007). O século de facadas não cumpriu o que insistia, não matou Luís, não matou o-que-não-podia-morrer dentro daqueles que matavam o corpo mortal de Luís. As facadas não eliminam, marcando as fronteira daquele que mata para garantir que é diferente do que é morto - 'mato, não porque és diferente de mim, mas para insistir, garantir e provar que sou diferente de ti' -; mas, pelo contrário, expõem cada vez mais o dentro que jorra marcando - lembrando - se misturando - as mãos de quem esfaqueia. A faca que se suja de sangue, tenta esfaquear mais uma vez para tentar se limpar... e não se limpa, apesar das cento e duas facadas. Zé lembra que Luís não morreu nas mãos de seu assassino, lembra que os "vestígios" da "bichona assassinada" não se perdem, mas passam a constituir outros corpos - o dele inclusive revelando a contínua agência das "emanações imortalizadas deste Corpo" (CORRÊA, 2007).

Transvive há mais de um Século de Facadas!

Quantas bastariam pra matar seu corpo de mortal?

E os assassinos apaixonados

Facadas

se perguntavam

Facadas

E quantas para Matar?

Facadas

Suicidar?

Facadas

Concentradas?

Facadas

epifanisadas?

Facadas nesse Corpo Luíz, Facadas sangrando sangue Facadas 


\author{
sangrando emanações , \\ Facadas \\ vitais, \\ Facadas \\ eróticas, \\ Facadas \\ homoeróticas, \\ Facadas \\ poéticas, \\ Facadas \\ cômicas, \\ Facadas \\ trágicas, \\ Facadas \\ musicais, \\ Facadas \\ Nesse corpo Luíz \\ Facadas \\ que não morre \\ Facadas \\ Apolo inCorporado \\ Facadas \\ impecável, \\ Facadas \\ elegante \\ Facadas \\ sorriso largo constante \\ Facadas \\ Palhaço! \\ Facadas \\ Dionísios! \\ Facadas \\ Amante! \\ Facadas
}

Esse Corpo-Alma Enfeitiçado

Estava dentro dos Corpos Assassinos

ATerrorizados

Com a Beleza

Matar o que não Morre

Dentro ou fora dos Corpos Assassinos

Com Milênios de Facadas no Assassinado
Os Assassinos Trágicos Bodes

Que clamam

'Chega de Bode!'

Não se assumem Bodes

Guardam-se em Armários

Tentam suicidar o que está lá dentro

Escondido

O divino mortal apaixonado perdido.

Transvive há mais de um Século de Facadas!

Quantas bastariam pra matar seu corpo de mortal? (CORRÊA, 2007)

Zé lembra que Luís transvive. Se sua vida foi transviada, não seria diferente na morte, que agora por ele era subvertida, invertida, rasurada e transformada - Luís transvive e nos lembra que vidas não devem ser dadas como mortas. O que as narrativas mestras (dos mestres) fazem é insistir no desaparecimento, na foraclusão de seu corpo abjeto e, principalmente, no silenciamento através da morte. Subvertendo essa narrativa, o Teatro Oficina UzynaUzona, zelado por Zé Celso, todos os dias 23 de dezembro celebram - nos mesmo horário do assassinato de Luís - o chamado dia da Ethernidade de Luís A referência ao éter (ether) rememora a personificação grega do céu sem limites e a substância que gregos e gregas antigas associavam à ubiquidade, um fluido sutil e rarefeito que em tudo estava e era respirado pelas Deusas e Deuses. Em grego Aîń $\rho$ (transliterado Aithếr) é derivado do verbo $\alpha i \theta \omega$ (aithô), queimar ou ainda - tal como purpurina - fazer brilhar

todos os dias 23 de dezembro, as $14 \mathrm{~h} 30$ cultivamos na agricultura teatral este Corpo chamamos dia da Ethernidade de Luís nós, da Associação Cambiante 
Teatro Oficina UzynaUzona, tiramos férias depois desse dia.

Estes ritos inspiraram sempre Nossos anos sequentes. As emanações imortalizadas deste Corpo, vem trazendo a dificílima mas poderosíssima revolução cultural brazyleira antropofágica, vivida em nossos Corpos. Os vestígios de Luís, 'essa bichona assassinada' como na Rádio gritava o Atanásio, em seu Armário Boçal,vem nos inspirando todos os fins-começo de ano. (CORRÊA, 2007)

Na peça Acordes - versão antropofágica da ópera de Bertolt Brecht e Paul Hindemith Das Badener Lehrstück Vom Einverständnis, de 1929-cuja estreia pelo Teatro Oficina ocorreu no dia 08 de novembro de 2010 e terminou sua temporada do dia da Ethernidade de Luís, há uma cena chamada de "contemplação dos mortos" em que é projetada a foto de Luís Antônio Martinez Corrêa, diante da qual o coro invoca sua presença saudando-presente! Atrizes, atores e o público começam então a berrar o nome de nossos mortos-que-não-morreram com um coro que responde a cada nome-presente! Presente! Presente! Tratase de um rito de invocação que retoma, de forma decolonial, concepções não-ocidentais da morte. Sabemos que no Ocidente, a morte foi isolada e se tornando repelida, maldita e interdita, contudo o saber afro-diaspórico brasileiro nos ensina que um fundamento de continuidade das comunidades é o culto às suas e aos seus ancestrais, tomando-as não como estatuetas simbólicas, mas como permanentes agências que continuam a atuar na comunidade e a participar da significação da vida: as emanações imortalizadas da Luis - essa vida actante imortal.

Em mundo que torna a morte interdida - e que torna insignificante a vida de pessoas subalternizadas - presentificar a existência de nossas mortas e mortos é um exercício de blasfêmia. Trata-se da construção de narrativas voltadas para irreverência do que é considerado inviolável: a morte, o silenciamento, a opressão. Blasfemar, como lembra Donna Haraway (2000), significa levar as coisas a sério e não abandoná-las, mas encarar dentro das comunidades a importância do enfrentamento da inviolabilidade. A comunidade LGBT, ao blasfemar contra a morte dizendo que não adianta tentar nos eliminar que somos da ordem do brilho, da contaminação e da ubiquidade, afirma a ethernidade de nossas existências. Nesse movimento, LGBT se deslocam do pensamento dominante - aquele que a poeta lésbica francesa Monique Wittig (1992) chamou de straightmind (pensamento hétero, reto, correto, sóbrio, ordeiro) - apontando a própria distinção entre vida e morte como uma distinção da ideologia hétero.

A noção de ethernidade se alicerça em um conceito de memória e de comunidade. Falar de uma comunidade LGBT, ou de uma comunidade de pessoas que não seguem a heterossexualidade hegemônica e a cisnormatividade, não é falar de um grupo, nem mesmo de uma população. A noção de comunidade não é e nem pode ser equivalente a noção de grupo (seja de um grupo populacional conectado por uma identidade externa ou de um grupo que se reúna em torno de uma identidade estratégica para uma luta), a noção de comunidade que adotamos é eminentemente cultural 
e cultura ganha aqui o sentido de cultivo, ou melhor, de terreno de cultivo, ou ainda, terreiro de cultivo. Citando Zé Celso, "Cultura cria Cosmos - não grupos. Cria maneiras de ler, interpretar, viver a Vida no Mundo." Por isso, membros dessa cultura não devem ser compreendidos como indivíduos culturais (representantes mais ou menos legítimos da identidade de um agrupamento), mas são o que Antonin Artaud chamou de "atletas afetivos", aquelas e aqueles que por meio de um arcabouço de cultivo exercitam seu corpo e sua existência para contagiar, afetar, transmitir o invisível. Como afirma Zé Celso, contagiado pelas emanações imortalizadas de Artaud, o atleta afetivo é sempre duplo: O DUPLO DO POETA / É O BODE CANTOR / ETERNO CORPO FÍSICO ETERNO.

Ao pensar em cultura como terreiro de cultivo, assumimos uma noção afro-diaspórica de memória como invocação. Uma memória que não é representada pelo silêncio, por interditos, mas pela invocação em cantigas, poesias, desejos e corpos. A construção de uma memória é o exercício de fazer corpos presentes. Para os nossos mortos não queremos minutos de silêncio, mas berros coletivizadores-Presente! - Presente! - Presente!

\section{Nosso AFETo, NOSSA AFETAÇÃo}

Michel Foucault, debatendo a necessidade de "realizar criações culturais" (FOUCAULT, 2004, p.262) em um movimento de construção de uma cultura guei, afirma que nossa autoidentificação não deveria se ligar a uma afirmação de uma substância, uma homossexualidade-coisa traduzida por nossa cultura. Pelo contrário, nossa autoafirmação deveria se emaranhar em realizações culturais com o objetivo não de nos afirmamos gueis, mas, antes de tudo, de "criar um modo de vida gay. Um tornar-se gay." (FOUCAULT, 2004, p.261). Seguindo esse caminho, o recente livro de David M. Halperin (2014) possui um título interessante: How to be Gay [Como ser Gay]. Esse livro defende a perspectiva de que ser gay não é uma identidade, mas diz respeito a uma orientação cultural, propondo que a viadagem - em seus termos, gayness seja pensada como cultura.

Ser gay envolve um conjunto de atitudes e valores, compõe uma orientação cultural. Implica uma sensibilidade refinada, um elevado sentido estético, uma sensibilidade particular para a moda e diferentes estilos, uma relação não-padrão para objetos de cultura dominante, uma rejeição de gostos comuns, bem como uma perspectiva crítica sobre o mundo hétero e uma coletividade partilhada, mas mesmo assim com uma visão singular do que realmente importa na vida. (HALPERIN, 2014, p.10, trad. nossa)

Ser gay, portanto, não é para Halperin sinônimo de alguém que realiza práticas homoeróticas, mas é uma forma distinta de ser diante da cultura hegemônica que revela um enraizamento em um arcabouço cultural de uma comunidade subalternizada levando aquele que se torna gay a ter uma perspectiva diferencial na forma de se relacionar com o mundo.

Essa distintiva forma de ser gay, além disso, parece estar enraizada em uma maneira particular de sentimento bicha [queer]. E dessa forma bicha [queer] 
de sentimento - essa subjetividade bicha [queer] se expressa através de uma maneira particular e dissidente em relação aos objetos culturais (filmes, músicas, roupas, livros, obras de arte) e as formas culturais em geral (arte da arquitetura, ópera e música teatro, pop e disco, estilo de moda, emoção e linguagem). Como uma prática cultural, a homossexualidade masculina envolve uma maneira característica de receber, reinterpretar, e reutilizar a cultura dominante, de decodificar os significados heterossexuais ou heteronormativos já codificados nessa cultura dominante, a fim de que eles vêm para funcionar como veículos de um significado gay ou bicha [queer]. (HALPERIN, 2014, p.10, trad. nossa)

Sendo uma orientação cultural, participar da cultura gay não requer que a pessoa seja gay, mas que partilhe dessa forma de ser, sentimento, subjetividade. No Brasil, por exemplo, é notório que mulheres heterossexuais cisgêneros foram grandes produtoras culturais gays, como Carmem Miranda, Maria Alcina e Elke Maravilha. Pensar em termos de comunidade culturais, e não de agrupamentos de indivíduos que partilham a mesma identidade, permite olhar de uma outra perspectiva que não as das cisões presentes no movimento social. Claudia Wonder (São Paulo, 1955-2010), cantora, atriz, compositora e performer travesti brasileira, aponta que ao pensarmos em uma "cultura gay" é fundamental visibilizar não somente que as travestis compõem essa cultura, mas que durante muitas décadas a prática cultural do travestismo (o sufixo 'ismo' é utilizado por Wonder (2008) enfatizando a prática cultural, sem nenhuma conotação de doença) foi o principal ícone da ideia de "gay". Mesmo que a maior parte das travestis organizadas em movimento social não reivindiquem como termo identitário a palavra gay; no âmbito cultural, Cláudia Wonder (2004) destaca que não se pode apagar o papel histórico das travestis na constituição dessa cultura. Lamenta que nos últimos anos a comunidade LGBT tenha cristalizado em seu meio o que chama de "ciranda de preconceitos" (WONDER, 2008, p.163), instaurando uma série de divisões e antagonismo motivados por preconceitos internalizados: "o gay não gosta da travesti, que por sua vez não o tolera também. A bichinha pintosa de quem ninguém gosta e a lésbica que não gosta de se misturar com travestis; além dos modernos que não assumem ser GLS ou isso ou aquilo, e por aí afora" (WONDER, 2008, p.163).

Wonder contrasta esse cenário rememorando sua entrada no universo gay na sua juventude em meio a Praça da República, onde lhe foram apresentadas figuras míticas como Lola, Micheli Miss Universo, Nana Voguel, Miss Biá e Dinamarca que foram suas primeiras professoras na vida gay. Nesse tempo a coesão da comunidade tinha laços na cultura gay, em especial na prática cultural do travestismo. Nas palavras de Claúdia Wonder, “acima de qualquer coisa, é o travestismo que representa como um todo essa cultura (gay)". Com extremo carinho e respeito, Cláudia rememora Rogéria, Valéria, Lorena e outras artistas travestis e transformistas de teatro e de shows como os maiores ícones de nossa comunidade, de forma que tanto as travestis e as transexuais, como os 
homens homossexuais, a despeito das suas diferenças de identidade, sentiam-se representadas por essas produtoras culturais.

Com uma narrativa histórica que passa pelo Miss Brasil Gay, pelos concursos dos mais belos transformistas do Silvio Santos, dos shows de travestis, Dzi Croquettes, As gigolletes, O que éque a boneca tem, Boys meet Boys, A gaiola das loucas, Roberta Close, Thelma Lipp, drag queens e seu próprio show $\mathrm{O}$ vômito do mito, Claudia Wonder (2008) nos revela o quanto a cultura gay é base para coesão de nossa comunidade, promovendo conexões e superando cisões individualistas. A estética da prática cultural do travestismo carrega em essência o que Cláudia enuncia a partir do Manifesto da Guerrilla Travolaka, coletivo autônomo de Barcelona, clamando por uma comunidade de piratas, trapezistas e guerrilheiros do gênero, como potência para "nos apoderar do gênero, redefinir nossos corpos e criar redes comunicativas livres e abertas para nos desenvolver, nas quais qualquer um possa construir seus mecanismos contra as pressões de gênero" (WONDER, 2008, p.71). Cláudia Wonder reivindica como valores revolucionários de nossa comunidade "a ambiguidade como identidade", "a beleza da androgenia" e "a anarquia do gênero" (WONDER, 2008, p.71).

David Halperin investigando a constituição da orientação cultural gay aponta que podemos pensar em dois movimentos distintos, mas complementares. O primeiro é o que ele chama, mais especificamente, de uma cultura gay produzida por pessoas que pela primeira vez na história criaram obras que apresentaram diretamente, abertamente e explicitamente a vivência da homossexualidade e das expressões diversas de gênero, tais como são vividas ou poderiam ser vividas. Falando especificamente das representações da homossexualidade masculina, Halperin (2012) cita autores como Walt Whitman, André Gide, Thomas Mann, Marcel Proust, Radclyffe Hall, Jean Genet, e James Baldwin. No Brasil, de forma menos excludente, incluindo representações da lesbiandade e da transexualidade, mais ainda de forma precária inviabilizando muitas produtoras que precisam ser presentificadas, poderíamos citar autores e autoras como João do Rio, Darcy Penteado, João Silvério Trevisan, Aguinaldo Silva, Mario Faustino, Cassandra Rios, Antônio Botto (que embora português, produziu no Brasil), Valery Pereleshin (que embora russo, produziu no Brasil), Walmir Alaya, Leila Miccolis, Paulo Augusto, Anderson Herzer, Lóris Adreon, Fernanda Farias de Albuquerque, Vange Leonel, Elizabeth Bishop (embora norte-americana, produziu no Brasil), Anna França, Luís Capucho e Cassiano Nunes, compositores como Tuca, Leci Brandão, Ângela Ro Rô, e novamente Vange Leonel e artistas plásticos como Hamilton Lima e novamente Darcy Penteado.

O outro movimento é o que David Halperin (2012) chama de uma subcultura gay. Com esse termo, o autor não se refere a produtos culturais menores mas de um movimento de apropriações culturais da cultura dominante, com práticas que depende dos signos da cultura hegemônica, mas que desenvolve uma relação parasitária subversiva 
que deslocam esses signos e criam novos sistemas culturais.

Uma subcultura não é a mesma coisa que uma cultura. A dinâmica de suas formações, seus objetivos e propósitos e suas políticas são todas necessariamente diferente. Uma subcultura é uma relação (se não adversária) de oposição a um conjunto já existente de valores culturais oficiais e refere-se, explícita ou implicitamente, a um mundo que não é sua própria criação independente. É uma expressão de resistência a uma cultura dominante e um desafio a uma ordem social. (HALPERIN, 2012, p.298, trad. nossa)

No caso dos Estados Unidos da América, David Halperin (2012) cita como exemplos dessas subculturas as performances das drag queens, o camp, o voguing, a apropriação de figuras icônicas como Judy Garland ou Joan Crowford e incorporações de músicas populares e de musicais da Broadway. Halperin (2012) aponta o exemplo da apropriação do grupo musical sueco ABBA que, com dois casais heterossexuais e nenhuma música tematizado a homossexualidade, se tornaram hinos gays. No caso do Brasil, é notório o caso da música Pavão Misterioso do cantor cearense Ednardo, que depois de ser popularizada como trilha da novela Saramandaia em 1976, foi apropriada como um manifesto da libertação gay. Também podemos citar a música Mesmo que seja eu, do Erasmo Carlos, símbolo de uma masculinidade hegemônica, cujos versos "Você precisa de um homem para chamar de seu, mesmo que seja eu" ganhou outros contornos na performance lesbiana de
Marina Lima, cantando essa música vestida de terno.

Uma das principais produções subculturais de nossa viadagem é o Bajubá (ou Pajubá), nome dado a um amplo léxico de termos originários de línguas africanas (yorubá, ewe-fon, djedje, bantu) proveniente das comunidades culturais afro-diaspóricas e com centenas de corruptelas de palavras do português, do tupi, do italiano e do francês. Criando uma linguagem interna das comunidades LGBT, o Bajubá permite a criação de uma rede de proteção para contextos de violência - tornando-se uma linguagem de "entendidos" estratégica para trocar informações sem que policiais percebam, por exemplo - e cria um permanente deslocamento irônico diante da linguagem hegemônica. Linguagem em permanente expansão, o Bajubá tornou uma arte de perverter a língua, alterando seu léxico, transformando sua cadência, africanizando seu vocabulário, traduzindo colonialmente expressões européias e feminilizando seus substantivos e artigos. A partir desses movimentos, o Bajubá provoca uma constante ironização da língua hegemônica que a revela como manifestação da dominação e simultaneamente escapa dela. Recentemente foi lançado um dicionário de termos do Bajuba, Aurélia: A dicionária da língua afiada, cujo o verbete "aurélia" já evidência essa arte da perversão:

Aurélia-S.f.1. Bicha metida e conhecedora profunda do bajubá, jurando que sabe de tudo; 2. Bicha filóloga, lexióloga, eloquente, googleóloga, control-efóloga, eustômica, disléxica, prolixa e extremamente divertida. 3. Bicha 
rica, dona de ilha, que não tem medo de comprar os maridos, uns seixas; 4 . Meu cu. (VIP \& LIBI, 2006, p.21).

O registro historiográfico e a salvaguarda da subcultura impõem uma dificuldade. Muitas vezes essas produções culturais não estão condensadas em bens culturais, haja vista que os bens podem ser exatamente os da cultura dominante ao passo que a produção cultural propriamente LGBT estaria na sua recepção por uma sensibilidade diferenciada. A noção de sensibilidade foi utilizada por Susan Sontag (2014) justamente para pensar o camp. Nossa dificuldade é que o historicismo só conhece a história dos bens culturais ou a história das ideias, dessa forma uma historiografia das subalternas precisa construir uma história das sensibilidades. Sontag (2014) sabia que para esse escopo era necessária a construção de novos métodos de investigação, de levar a sério tanto a nossa atração, quanto a nossa repulsa por essas sensibilidades.

Falar de uma sensibilidade (distinta de idéia) é uma das coisas mais difíceis; entretanto, existem razões especiais para o Camp, em particular, jamais ter sido analisado. Não se trata de uma forma natural de sensibilidade, se é que isto existe. Na realidade, a essência do Camp é sua predileção pelo inatural: pelo artifício e pelo exagero. [..] Sinto-me fortemente atraída pelo Camp e quase tão fortemente agredida. É por isso que quero falar a seu respeito e por isso posso fazê-lo. Pois ninguém que compartilhe sinceramente de uma determinada sensibilidade pode analisá-la; só pode, seja qual for a sua intenção, mostrá-la. Para designar uma sensibilidade, traçar seus contornos e contar sua história exige-se uma profunda afinidade modificada pela repulsa. (SONTAG, 2014, p.oI)

David Halperin (2012) aponta como uma das principais práticas culturais da subcultura gay masculina o camp, palavra sem tradução para o português mas que pode ser facilmente reconhecida em nossas práticas - a predileção pelo exagero, pelo dramático, pelo artificial e pelo tragicômico que talvez possa ser aproximada da sensibilidade viada brasileira presente na ideia de afetação. Para Halperin, o camp se caracteriza pela capacidade de subverter tragédias e situações de violência, adicionando humor em situações de horror e nos ensinando a rir como forma de empoderamento diante das opressões cotidianas. "A cultura gay masculina" - afirma Halperin - "tem uma longa história de rir de situações que para os outros são horríveis ou trágicas". Como uma técnica de inversão do horror, o camp expõe uma tradição cultural gay-sedimentada em uma sensibilidade - de recusa da autocondenação social.

O que caracteriza o Camp é a sua recusa deliberada de auto-isenção da zombaria que lhe é dirigida no mundo social, bem como a sua tendência para tirar sarro e debochar de sua própria abjeção. O Camp não é apenas um modo de apropriação cultural, uma forma de reciclar a cultura dominante; também é produtivo, um impulso criativo com sua própria direção, uma estratégia para lidar com a dominação social. (HALPERIN, 2012, p. 203) 
Uma das principais contribuições de David Halperin (2012) para o desenvolvimento de um arcabouço conceituação de investigação da cultura e subcultura gay é a noção de gênero. O uso da palavra "gênero" no campo de estudos do gênero e da sexualidade no Brasil está bastante cristalizada como tradução da palavra inglesa gender, a categoria que se refere a produção sexuada de diferença sociais. Contudo, seguindo Halperin, utilizaremos a palavra gênero como tradução da palavra inglesa genre, utilizada para se referir a gêneros literários. Com esse termo, David Halperin (2012) buscou investigar formas sociais e culturais em sua positividade, como produções que podem ser compreendidas de forma autônoma para sua investigação e interpretação. Com isso, Halperin (2012) quer conceber o estudo que propõe da cultura gay mais como uma investigação que se assemelha à Poética, do que à Sociologia ou à Antropologia, complementando as importantíssimas investigações dessas disciplinas, mas evitando reduzir as produções culturais a expressões ou produtos de processos sociais. A noção de gênero, na crítica literária, aponta para uma regulação reconhecível - embora mais ou menos flexível - de apropriação da linguagem. Os gêneros culturais - sendo o camp um exemplo central - também se constituiria a partir de um trabalho regulatório reconhecido feito por práticas sociais, discursivas ou não, mas que apresenta sempre uma relação criativa e criadora no uso da linguagem e das performances de práticas sociais.

[...] gêneros de discurso performam a mesma função reguladora em práticas discursivas codificadas não no campo da composição e recepção literária, mas na esfera da comunicação, comportamento social e interações pessoais - definindo assuntos apropriados e importantes, formas de relação interpessoal e estilos de comunicação. Nesse sentido, gêneros não são somente formais mas também pragmáticos. Eles fornecem às pessoas, em suas práticas diárias, com meios concretos de interação com outro e negociando situações sociais específicas - e eles os instruem em formas certas de se fazer. (HALPERIN, 2012, p. 132)

A partir da investigação de gêneros culturais LGBT, podemos inclusive criar campos de estudos comparativos entre comunidades de diferentes nacionalidades e contextos sociais. Que aproximações podemos fazer do gênero do bitching (e as suas práticas culturais do reading e throwingshade) com a nossa gongação (e as práticas culturais do congar, do carão e das construções de narrativa de superioridade - "lacrar", "fechar", "sambar na cara das inimigas")? Se compreendemos o butching como gênero da cultura lesbiana estadunidense, que comparações podemos fazer com a nossa sapatonice brasileira? A noção de gênero pode permitir investigar as conexões entre sujeitos que se identificam a partir de diferentes identidades sociais - o travestismo, por exemplo, é para Cláudia um gênero cultural que conectava gays e travestis -, assim como identificar diferenças de classe, raça, etnia, sexo e construção corporal a partir das diferenças dos trabalhos regulatórios feitos para produção de gêneros. No livro de How to be Gay, David Halperin (2012) busca identificar especificamente os gêneros 
que compões as comunidades de gays masculinos, levando-nos a perguntar quais gêneros que compõem, de forma exclusiva ou não, solidificados ou ainda em construção, as comunidades de travestis, de homens transexuais, de mulheres transexuais, de mulheres lésbicas e bissexuais? Como se tornar lésbica, trans, travesti ou bissexual?

A reflexão sobre o Campe, mais especificamente, sobre como a produção de sensibilidades responde-e confronta-e interroga-a violência do mundo social, também permite que investiguemos de forma mais positiva como LGBT brasileiras re-existem (para não dizer resistir, palavra mais anticultural e destruidora de cosmos, segundo Zé Celso) diante da violência - e não somente como a sofremos ou a suportamos. Um grande exemplo é como a produção teatral de Zé Celso foi transformada pelo assassinato de seu irmão. Percebendo que um mundo em que alguém é assassinado com 107 facadas é eminentemente trágico, Zé Celso decide nunca mais montar drama:

Foram 107 facadas. Com uma, você mata uma pessoa. As outras todas estão, na verdade, matando uma outra coisa, que está em quem mata e não em que está sendo morto. O Luís era uma figura formidável, mais alegre que eu, mais livre que eu... A geração dele cagava e andava para tudo, brincava com ácido como se fosse drops. Mais que a censura, mais que a prisão, mais que o exílio, a morte do Luís foi definitiva para mim: foi quando eu me dei conta de que a vida é trágica. Ali, eu rompi com o drama. Eu rompi com tudo, com as regras, com os dogmas $(\mathrm{O}$ POVO, 2015).
Com re-existência ao trágico, Zé Celso transformou seus afetos em afetação criando o gênero da tragycomedyorgia, cuja maior força está em, ao encarar a tragédia da vida, acionar a potência corrosiva do cômico e do orgástico.

\section{REFERÊNCIAS}

BENJAMIN, W. Obras escolhidas. Vol. 1. Magia e técnica, arte e política. Ensaios sobre literatura e história da cultura. Tradução de Sérgio Paulo Rouanet. São Paulo: Brasiliense, 1987.

BENJAMIN, W. Obras escolhidas II: Rua de mão única, São Paulo: Brasiliense, 1995.

CORRÊA, J.C. M.O corpo imortal do poeta Luis, 2007. Disponível em: http://www.teatroficina. com.br/posts/126. Acesso em: 15 de dezembro de 2015

DANIEL, H.; MICCOLIS, L. Jacarés \& Lobisomens: dois ensaios sobre a homossexualidade. Rio de Janeiro: Achiamé/ Socci, 1983.

DANIEL, H. Meu corpo Daria um Romance. Rio de Janeiro: Rocco, 1984

DERRIDA, J. Mal do Arquivo: uma impressão freudiana. Tradução de Cláudia de Moraes Rego. Rio de Janeiro: Relume Dumará, 2001.

FOUCAULT, M. Michel Foucault, uma entrevista: sexo, poder e a política da identidade. Verve, Ed.5, 2004. Disponível em: http://revistas.pucsp.br/index.php/verve/ article/viewFile/4995/3537. Acesso em: 15 de dezembro de 2015.

HALPERIN, D. M. How to be Gay. Cambridge, Massachusetts: Bellnap Press, 2012.

HARAWAY, D. Manifesto ciborgue Ciência, tecnologia e feminismo-socialista no final do século XX. In: HARAWAY, D. KUNZRU, H. 
Antropologia do ciborgue: As vertigens do póshumano.Tradução de Tomás Tadeu $-2^{\mathrm{a}} \mathrm{Ed}$. Belo Horizonte: Autêntica Editora, 2000.

HERZER, A. Da Queda para o Alto. São Paulo, Editora Vozes, 1982

KRAMER, S., "Produção cultural e educação: algumas reflexões críticas sobre educar com museu" en: KRAMER, S., LEITE, M, I., Infância e produção cultural. Campinas: Papirus, 1998, pp. 199-215.

O POVO. Leia íntegra da entrevista com José Celso Martinez Corrêa. Disponível e m : ht t p:// www20.opovo.com.br/ app/opovo/paginasazuis/2011/01/24/ noticiasjornalpaginasazuis,2093293/leiaintegra-da-entrevista-com-jose-celsomartinez-correa.shtml Acesso em: 15 de dezembro de 2015.

SONTAG, S. Notas sobreocamp. (s/d) Disponível em: https://perspectivasqueeremdebate.files. wordpress.com/2014/06/susan-sontag_notassobre-camp.pdf. Acesso em: 15 de dezembro de 2015 .

TREVISAN, J. S. Paraíso Perdido, Paraíso Reencontrado. In: Devassos no Paraíso: a homossexualidade no Brasil, da colônia à atualidade. 4 ed. Rio de Janeiro: Record, 2000. p.429- 469 .

VIP, A. LIBI, F. Aurélia: a dicionária da língua afiada. São Paulo: Editora Bispo, 2006.

WITTIG, M. The Straight Mind and other essays. Boston: Beacon Press, 1992.

WONDER, C. Olhares de Cláudia Wonder. São Paulo: Edições GLS, 2008.

Recebido para publicação em 26 mar. 2017. Aceito para publicação em 10 nov. 2017. 